American Medical Journal 1 (2): 113-119, 2010

ISSN 1949-0070

(C) 2010 Science Publications

\title{
A Cross-sectional Study of Sexual Practices, Sexually Transmitted Infections and Human Immunodeficiency Virus among Male-to-Female Transgender People
}

\author{
${ }^{1,2}$ P.S. Saravanamurthy, ${ }^{2}$ P. Rajendran, ${ }^{1}$ Priya Maria Miranda, ${ }^{1,2}$ G. Ashok, ${ }^{1}$ Sai Subhasree Raghavan, \\ ${ }^{3}$ Julia H. Arnsten, ${ }^{1}$ L. Ramakrishnan and ${ }^{4} \mathrm{~S}$. Vijayakumar \\ ${ }^{1}$ Solidarity and Action Against The HIV Infection in India, No.78, Pushpa Nagar Main Road, \\ Nungambakam, Chennai-600034, Tamil Nadu, India \\ ${ }^{2}$ Department of Microbiology, Dr. ALM Post Graduate Institute of Basic Medical Sciences, Chennai, India \\ ${ }^{3}$ Department of Medicine, Albert-Einstein College of Medicine and Montefiore Medical Center, \\ New York, USA \\ ${ }^{4}$ Tamil Nadu State AIDS Control Society, Chennai, India
}

\begin{abstract}
Problem statement: Designing HIV interventions requires evidence on links between behaviors and elevated transmission risk that remains scanty for male-to-female Transgender (TG) people in India. Approach: In 2007, we carried out a cross-sectional study through convenience sampling of 131 TG aged > 18years, residing in Chennai at least prior to six months of the study. Sexual practices and perception towards STIs and HIV were identified through structured interviews. HIV and STIs were diagnosed from blood and urine samples. Associations among sexual practices, HIV/STI and alcohol use were analyzed using contingency tables. Results: The study participants had a mean age of sexual debut of 12.86 years. From the sample, $91 \%$ reported involvement with casual, paid and/or long-term sex partners at the time of the study and reported having anal sex in similar proportions across all three types of partners. More individuals failed to use condoms with long-term partners $(44 \%)$ than with casual $(17 \%)$ or paid $(9 \%)$ partners. Alcohol use was more strongly associated with multiple casual and paid partners than with exclusive long-term partners $(p<0.05)$. About 29\% reported sex under the influence of alcohol. $72 \%$ were diagnosed with least one STI, with viral STIs ranging from 8-48 and 18\% diagnosed with HIV. HIV-positive individuals could not be statistically distinguished from HIV-negative individuals on the basis of anal and oral sex, presence/absence of STI, inconsistent condom use or sex under the influence of alcohol. Conclusion/Recommendations: Given the extensive literature on associations between inconsistent condom use, unprotected anal sex, alcohol and HIV risk, the lack of difference between HIV-positive and negative individuals with respect to behaviors suggests that the entire sample represents a group needing primary or secondary prevention intervention. Partner reduction, consistent condom usage and sex under the influence of alcohol are areas for further research and program interventions among TG in Chennai, India.
\end{abstract}

Key words: Multiple sex partner, condom use, alcohol and prevention strategies

\section{INTRODUCTION}

In India, since the first Human Immunodeficiency Virus (HIV) case was detected in 1986 (Simoes, 1987) and sexual route remains the chief mode of transmission (National Alliance of State and Territorial AIDS Directors, 2009). HIV has had devastating impacts on both high risk groups and the general population (Harrison et al., 2005). HIV/AIDS surveillance has documented HIV prevalence $0.60 \%$ among ante-natal clinic attendees $3.74 \%$ among STD clinic attendees, $6.92 \%$, among injecting drug users, $4 \%$ among female sex workers and $6.41 \%$ among men having sex with men (MSM) (National AIDS Control Organization, 2008). HIV/AIDS surveillance in India classifies male-to-female transgender people under the MSM umbrella and has estimated prevalence for this mixed group until 2007.

"Transgender" an umbrella term coined in the 1970s, includes persons whose gender identity, Main Road, Nungambakam, Chennai-600034, Tamil Nadu, India Tel: 91-44-28173947 Fax: 91-44-28173948 
expression or behavior does not conform to societal gender norms associated with sex at birth and they are grouped by their gender as Male-To-Female (MTF) and Female-To-Male (FTM) (Kenagy, 2005; Grieve-Smith, 2006) In addition to those who seek to be recognized as being of the gender different from the one they were assigned at birth and even pursue surgical options to align their anatomy with their gender-identity, some may consider themselves to fall "between" genders, may not identify strictly to one gender or the other and may identify themselves as neither fully male nor female (Venkatesan et al., 2004).

In the Indian sub-continent, MTF transgender people are called Kinnar, Hijra, Khusra, Jankha, Paavaiyaa or Aravani in various regions. Hijra is the commonly used neutral term, while Ali and Chakka are derogatory terms used in the subcontinent. In English, transgender people are also called eunuchs (Kira and O'Donovan, 1996). Male-to-female transgender people in India are highly stigmatized, starting from their biological family and later from society at large. This has made the transgender community isolated from mainstream life and a non-biological kinship system has arisen called Jamaath, with elder transgender people as Gurubhai and their younger disciples as Chela. The Jamaath system has created a closely knit network, which enables the community to stay well connected and to provide support between themselves. The pervasive stigmatization of the male-to-female transgender community in India has prevented transgender people from seeking health care (Venkatesan et al., 2004).

Studies outside India have provided data on sexual practices and the prevalence of STIs and HIV among male-to-female transgender people. A review of 307 studies conducted between 1988-2006 among transgender people in the United States reported an average HIV prevalence of $27.7 \%$; with $31.7 \%$ reported having multiple sex partners, $44.1 \%$ reported practicing unprotected anal receptive intercourse and 39.3\% reported sex under the influence of alcohol, in contrast only $15 \%$ perceived themselves to be at risk for HIV (Jeffrey and Herbst, 2008). In Indonesia, HIV prevalence among transgender people has been estimated at $22 \%$, with $59.3 \%$ of transgender people reported having unprotected anal intercourse (Pisani et al., 2004). In Pakistan, HIV prevalence among the transgender community has been estimated at $2 \%$, while rates of other STIs has been estimated to be much higher with Syphilis 62\%, N. gonorrhea 29\% and Chlamydia 18\% (Khan, 2006).

In India, very few studies have reported the prevalence of sexual practices, STIs and HIV among male-to-female transgender people. A recent study reported 12\% HIV prevalence among transgender people in Tamil Nadu (Brahmam et al., 2008) and $18.1 \%$ (Kenagy, 2005) as India prevalence. $65 \%(\mathrm{~N}=$ 229) reported prevalence of condom usage during anal intercourse and 50\% ( $\mathrm{N}=229)$ sex under the influence of alcohol in India (Sharma Mahendra et al., 2008). Similarly, another study in Mumbai, India, reported that $40 \%$ of transgender people were HIV positive, $25 \%$ were VDRL reactive, $85 \%$ reported receptive anal sex, $49 \%$ had more than 10 partners in the last one month and $64 \%$ had sex work as occupation (Kumta et al., 2006).

Prevalence of HIV was associated with HCV and Syphilis among male-to-female transgender people in Mumbai, India (Kumta et al., 2002). There remains a gap in data linking sexual practices to prevalence of STIs and HIV among male-to-female transgender people in India. The data on Sexually Transmitted Infection (STI) prevalence and the risk behaviors associated with STIs may assist with estimating the number of male-to-female transgender people at risk for HIV.

To address these issues, we conducted a crosssectional study to document the demographic characteristics, educational patterns, occupations, substance abuse and high risk sexual practices that make the transgender community in Chennai, India, vulnerable to STIs and HIV. We also collected clinical and laboratory evidence for Syphilis, Neisseria gonorrhea, Chlamydia trachomatis, Hepatitis B Virus (HBV), Hepatitis C Virus (HCV), Herpes Simplex Virus (HSV) (Cowan et al., 2002) types 1and 2 and HIV. We hypothesized that (i) sex under the influence of alcohol would be associated with multiple partners and/or casual partners and/or paid partners rather than exclusive life partners, (ii) positive HIV status would be associated with presence of bacterial and/or viral STIs and receptive anal sex practice.

\section{MATERIALS AND METHODS}

Study period, recruitment criteria and ethical approval: In June 2007, we recruited a convenience sample of adult ( $\geq 18$ years of age) self-identified maleto-female transgender people, irrespective of emasculation status and/or attire. Participants had to have resided in Chennai for at least the preceding six months. The study protocol and all field-tested tools were approved by the Institutional Review Board (IRB) of the Dr. ALM Post Graduate Institute of Basic Medical Sciences, University of Madras, India.

Recruitment strategy: Study participants were approached in the residential area of the male-to-female 
transgender people by outreach workers and study procedures explained prior to registration and repeated prior to informed consent by the interviewer. Study participants were interviewed with semi-structured questionnaires, followed by a clinical physical examination and blood $(5 \mathrm{~mL})$ and urine sample collection. All the study participants were provided Rs.100 (2 USD) for travel and refreshments.

Data collection: An unlinked anonymous coded semistructured questionnaire was used to collect details on demographic, socio-economic, education, migration, sexual behaviors/practices, substance abuse, knowledge of STIs/ HIV/AIDS, STI disease history and HIV/AIDS diseases status of the study participants were collected. Serum samples were tested for Syphilis using RPR and TPHA, for HSV-1 IgG and HSV-2 IgG and for HBV and HIV. Urine samples were used for C. trachomatis and N. gonorrhoea using duplex PCR tests (Roche Molecular system Inc.).

Statistical analyses: Sexual partners of self-identified male-to-female transgender people were classified into three categories based upon the nature of association and transactions of cash or kind: (1) life partner: With whom the participant maintains a long term relationship, may or may not be continuously living with and whom she considers a husband; (2) Casual partner: with whom the participant has sex without transaction of money, but is not a life partner and (3) paid partner: With whom the participant has sex and receives cash or equivalent. Alcohol consumption was measured by frequency of intake ranging from daily, weekly twice or thrice, or monthly, while sex under the influence of alcohol was categorized as (1) always, (2) rarely and (3) never. Statistical analyses were done using SPSS ver. $10^{\odot}$. Correlation and association between variables such as alcohol consumption, types of sex partner and condom usage were calculated.

\section{RESULTS}

Demographic characteristics (Table 1): The mean age of study participants was 27.63 \pm SD 8.77 years, with $50 \%$ of study participants in the age group of 1825 years. The mean age at which the study participants' realized their gender identity was $11.53 \pm$ SD 3.41 years (Table 2). The mean age of sexual debut was $12.86 \pm \mathrm{SD}$ 3.62 years. $98 \%$ of study participants reported their initial sexual act was with a male partner and $69 \%$ initiated with consent of the partner.
Although majority of the study participants had basic education (6th-12th grade-59\%), major means of income generation was through seeking alms $(50 \%)$ or sex trade $(49 \%)$. The population was mobile, with $69 \%$ of participants having traveled outside the State of Tamil Nadu during their life time and $48 \%$ of participants having stayed outside the State of Tamil Nadu for at least six months, usually in Mumbai, in the State of Maharashtra, which was about 640 miles (1030 $\mathrm{km})$ by road.

Table 1: Demographic and clinical characteristics

\begin{tabular}{|c|c|c|}
\hline Factor & Percentage & Mean \pm SD \\
\hline Age (years) & & $27.63 \pm 8.77$ \\
\hline $18-25$ & 50 & \\
\hline $26-35$ & 36 & \\
\hline $36-45$ & 7 & \\
\hline $46-55$ & 4 & \\
\hline $56-65$ & 2 & \\
\hline $66-75$ & 1 & \\
\hline Age of relocation from birth place & & $17.32 \pm 8.23$ \\
\hline \multicolumn{3}{|l|}{ Travel to another state } \\
\hline \multicolumn{3}{|l|}{ for at least 6 months } \\
\hline \multicolumn{3}{|l|}{ Within state (inter-districts) } \\
\hline Madurai & 21 & \\
\hline Trichy & 12 & \\
\hline Coimbatore & 9 & \\
\hline Salem & 6 & \\
\hline \multicolumn{3}{|l|}{ Within the country (inter-state) } \\
\hline Two states & 24 & \\
\hline Three states & 7 & \\
\hline \multicolumn{3}{|l|}{ Education } \\
\hline None & 14 & \\
\hline Primary (I-V) & 16 & \\
\hline $\begin{array}{l}\text { Secondary and higher secondary } \\
\text { (grade 6th-12th) }\end{array}$ & 59 & \\
\hline Diploma & 5 & \\
\hline Under graduate & 5 & \\
\hline Post graduate & 1 & \\
\hline \multicolumn{3}{|l|}{ Housing } \\
\hline Tiled house & 40 & \\
\hline Terraced & 29 & \\
\hline Thatched house & 21 & \\
\hline Flats/apartment & 6 & \\
\hline Pavement/platform & 5 & \\
\hline \multicolumn{3}{|l|}{ Income generation } \\
\hline Seeking alms from shops & 50 & \\
\hline Sex work & 49 & \\
\hline Working in voluntary organization & 14 & \\
\hline House maid & 8 & \\
\hline \multicolumn{3}{|l|}{ STIs prevalence including HIV } \\
\hline HIV-1 and 2 & 17 & \\
\hline \multicolumn{3}{|l|}{ Syphilis } \\
\hline TPHA reactive & 16 & \\
\hline RPR reactive & 8 & \\
\hline RPR and TPHA & 5 & \\
\hline N. gonorrhoea & 1 & \\
\hline C. trachomatis & 1 & \\
\hline $\mathrm{HBV}$ & 8 & \\
\hline HSV-2 (IgG) & 29 & \\
\hline HSV-1 (IgG) & 48 & \\
\hline
\end{tabular}


Am. Med. J. 1 (2): 113-119, 2010

Table 2: Prevalence of high risk behaviors, STIs and HIV

\begin{tabular}{|c|c|c|}
\hline Factor & Percentage & Mean \pm SD \\
\hline $\begin{array}{l}\text { Age of realization } \\
\text { of gender identity }\end{array}$ & - & $11.53 \pm 3.41$ \\
\hline $\begin{array}{l}\text { Age and circumstances } \\
\text { of sexual debut }\end{array}$ & - & $12.86 \pm 3.62$ \\
\hline Childhood friend & 25 & \\
\hline Relative & 21 & \\
\hline Neighbor & 20 & \\
\hline Family friend (adult) & 7 & \\
\hline Teacher & 7 & \\
\hline \multicolumn{3}{|l|}{$\begin{array}{l}\text { Sexual partners and } \\
\text { sexual practices }\end{array}$} \\
\hline \multicolumn{3}{|l|}{ Life partners $(N=63)$} \\
\hline Anal sex & 24 & \\
\hline Oral sex & 15 & \\
\hline Inter femoral sex & 27 & \\
\hline Always condoms & 43 & \\
\hline No condoms & 44 & \\
\hline \multicolumn{3}{|l|}{ Casual partners $(\mathrm{N}=80)$} \\
\hline Anal sex & 26 & \\
\hline Oral sex & 33 & \\
\hline Inter femoral sex & 38 & \\
\hline Always condoms & 59 & \\
\hline No condoms & 17 & \\
\hline \multicolumn{3}{|l|}{ Paid partners $(\mathrm{N}=85)$} \\
\hline Anal sex & 29 & \\
\hline Oral sex & 29 & \\
\hline Inter femoral sex & 54 & \\
\hline Always condoms & 75 & \\
\hline No condoms & 9 & \\
\hline \multicolumn{3}{|l|}{ Other risk behaviors } \\
\hline Alcohol consumption & $68(17-34 *)$ & \\
\hline Daily consumption & 22 & \\
\hline Thrice weekly & 1 & \\
\hline Twice weekly & 7 & \\
\hline Monthly once & 19 & \\
\hline Alcohol during sex & 29 & \\
\hline Tattooing & 43 & \\
\hline Hormonal injections & 29 & \\
\hline $\begin{array}{l}\text { Perceives self to be at } \\
\text { risk of acquiring HIV }\end{array}$ & 14 & \\
\hline $\begin{array}{l}\text { Perceives self to be at risk } \\
\text { of acquiring any STI }\end{array}$ & 17 & \\
\hline
\end{tabular}

Clinical characteristics: Although all study participants were clinically asymptomatic, $17 \%$ were found to be HIV-positive and $72 \%$ had laboratory evidence of having had at least one STI during their lifetime, including HSV-1 and HSV-2. The prevalence of Syphilis (ever) was 16\%, while the prevalence of a current Syphilis infection was 5\%. N. gonorrhea and C. trachomatis were each present in $1 \%$ of participants, HBV was present in $8 \%$, HSV-2 was present in $29 \%$ and HSV-1 was present in $48 \%$.

Sexual behaviors and practices (Table 2): Participants reported that their first sexual partners included childhood friends, relatives, neighbors, adult family friends and teachers. Participants were asked to categorize their different sorts of sex partners; $11 \%$ reported three different categories of sex partners: Life partners, casual partners and paid partners, 29\% of participants reported two categories of sex partners: casual and paid partners, $13 \%$ reported life and paid partners and $9 \%$ reported life and casual sex partners. In addition, $11 \%$ reported only life partners, $8 \%$ reported only casual partners and 19\% reported only paid partners. Among those with casual and paid partners, the number of such partners ranged from a minimum of two to a maximum of ten different individuals.

The most frequent form of sex was inter-femoral sex: $27 \%$ of participants reported inter-femoral sex with life partners, $38 \%$ reported inter-femoral sex with casual partners and 54\% reported inter-femoral sex with paid partners. Anal and oral sex were less common. Inconsistent condom usage was observed across all categories of sex partners, with condom use reported with $75 \%$ of paid partners, $59 \%$ of casual partners and $43 \%$ of life partners. Despite high risk sexual behaviors, self-perceived risk of STIs or HIV was low.

Alcohol and tobacco practice (Table 2): About 29\% of the study participants reported sex under the influence of alcohol. Among the study participants $68 \%$ of them reported alcohol use; this is higher than most national prevalence estimates in India among the general population, which range from $7 \%$ in the western states to $75 \%$ in the northeastern states, while in Chennai alcohol prevalence is $16.7-34.4 \%$ (Benegal, 2005). Among the alcohol users in this study population $22 \%$ consumed alcohol daily. As 59\% of study participants reported chewing tobacco, while 9\% reported smoking tobacco.

Needles and injections: About $43 \%$ of the study participants reported at least one tattoo, with $77 \%$ of these reporting receiving their tattoo under non-sterile circumstances. 29\% reported receiving hormonal injections for breast enhancement. None of the study participants reported injecting recreational drugs.

\section{Associations (Table 3):}

Alcohol use and high risk sexual behavior: Sex under the influence of alcohol was more common among participants with multiple types of sex partners (i.e., casual, paid and life partners) than participants with only life partners $\left(\chi^{2}=6.18, \mathrm{p}=0.017\right)$ and was also more common among participants with paid partners than with life partners $\left(\chi^{2}=4.1, \mathrm{p}=0.04\right)$. Positive HIV status $\left(\chi^{2}=3.136\right)$ and condom use, during sex under the influence of alcohol across types of sex partners is not statistically significant. 
Am. Med.J. 1 (2): 113-119, 2010

Table 3: Associations between alcohol, types of sex partners and condom use

\begin{tabular}{|c|c|c|}
\hline Factors & $\mathrm{n}(\%)$ & $\mathrm{p}$-value \\
\hline \multicolumn{3}{|l|}{$\begin{array}{l}\text { Alcohol consumption during sex, } \\
\text { stratified by type of sex partner }\end{array}$} \\
\hline \multicolumn{3}{|l|}{ Exclusive life partner } \\
\hline Sex under influence of alcohol & $2(15)$ & \\
\hline Sex not under alcohol influence & $11(85)$ & \\
\hline \multicolumn{3}{|l|}{$\begin{array}{l}\text { Multiple sex partners (includes life, } \\
\text { casual and paid) }\end{array}$} \\
\hline Sex under influence of alcohol & $52(55)$ & \\
\hline Sex not under alcohol influence & $48(51)$ & \\
\hline \multicolumn{3}{|l|}{ Casual sex partners } \\
\hline Sex under alcohol influence & $3(30)$ & \\
\hline Sex not under alcohol influence & $7(70)$ & \\
\hline \multicolumn{3}{|l|}{ Paid sex partners } \\
\hline Sex under alcohol influence & $6(55)$ & \\
\hline Sex not under alcohol influence & $5(45)$ & \\
\hline \multicolumn{3}{|l|}{$\begin{array}{l}\text { Association of alcohol consumption } \\
\text { during sex and type of sexual partner }\end{array}$} \\
\hline Exclusive life partner Vs multiple partners & & $0.017 *$ \\
\hline Exclusive life partner Vs casual partners & & 0.400 \\
\hline Exclusive life partner Vs paid sex partners & & $0.040^{*}$ \\
\hline Casual Vs paid sex partners & & 0.250 \\
\hline \multicolumn{3}{|l|}{$\begin{array}{l}\text { Association of condom use while having sex } \\
\text { under the influence of alcohol }\end{array}$} \\
\hline With life partners & & 0.700 \\
\hline With casual sex partners & & 0.434 \\
\hline With commercial sex partners & & 0.986 \\
\hline \multicolumn{3}{|l|}{ Association of HIV } \\
\hline Anal recipient with life partners & & 0.789 \\
\hline Anal recipient with casual partners & & 0.311 \\
\hline Anal recipient with paid partners & & 0.795 \\
\hline Oral sex on life partners & & 0.525 \\
\hline Oral sex on casual partners & & 0.625 \\
\hline Oral sex on paid partners & & 1.000 \\
\hline \multicolumn{3}{|l|}{ Association of HIV and STIs } \\
\hline Bacterial STIs & & 0.812 \\
\hline Viral STIs excluding HSV- 1 & & 0.777 \\
\hline Viral STIs including HSV-1 & & 0.733 \\
\hline
\end{tabular}

HIV and anal/oral sex: Chi-square analyses indicate HIV positive status is independent of the anal or oral sexual act in all three types of sexual partners in this study sample. HIV and STIs. Similarly, chi-square analysis indicates that present or past infection of STIs, is not significantly associated with HIV sero-status.

\section{DISCUSSION}

Community prevalence studies can assist in providing new strategies for reducing and controlling sexually transmitted infections, including HIV. Data from such studies can be used to assess the impact of interventions and to design new interventions. Hence, the World Health Organization has suggested that region specific studies be used as an STI surveillance mechanism (World Health Organization, 1999). Many studies around the world have documented the role of sexual practices in transmission of STIs and HIV
(Graham, 2004; Khan et al., 2008). The present study attempts to observe the role of sexual practices and the prevalence of STIs and HIV in the male-to-female transgender community through a biological-behavioral survey that includes sexual practices, substance abuse, tattooing, socio-economic, clinical and laboratory data on STIs and HIV.

The predominant age group $(18-35,66 \%, 86 / 131)$ of study participants and the study findings represent the existing practices of young adult male-to-female transgender people in Chennai. Early sexual debut of the study participants is a indicator of engaging in multiple partner sex (Harrison et al., 2005) and vulnerability to STIs (Christine et al., 2005). The study indicates that many subjects have moved away from their biological family within and out of their home states. Mobility is a factor previously reported to increase vulnerability to sexual behaviors and HIV (Lydié, 2004). Future research and program interventions should be designed considering the study population's high mobility and relocation from their birth place. Mumbai, a city where a majority of participants had temporarily moved to, is one of the commercial sex capitals of Asia and provides many opportunities for transgender people to enter the sex trade (Rani, 2008).

This study documented a $17 \%$ HIV prevalence among a male-to-female transgender population in the city of Chennai, higher than an estimate of $12 \%$ for the entire state (Brahmam et al., 2008; Mishra, 2009). Regarding STIs, we found that viral STIs, including HSV-1, HSV-2 and HBV, were more prevalent than bacterial STIs, including Syphilis, $N$. gonorrhea and C. trachomatis. Regardless of inclusion of HSV-1 which can be transmitted through non-sexual means, the association between viral or bacterial STIs with HIV is not statistically significant. This suggests that the HIV positive and negative sub-groups cannot be distinguished from each other based on presence/absence of these STIs. This lack of association needs to be explored in future studies and considered while designing future STI and HIV/AIDS interventions.

Considering the presence of risk factors such as alcohol use, multi-partner sex and inconsistency in condom usage among this study population, future interventions should focus on prevention, early detection and treatment of all STIs and HIV. In addition, vaccinations for HBV should be considered as one of the risk-reduction strategies to minimize the vulnerability to HBV and thus reduce the viral STI burden among male-to-female transgender people. 
Regarding sexual risk, future behavioral interventions should assess the role of inter-femoral sex in reducing and preventing the spread of STIs and HIV infection among transgenders. Earlier studies (Cowan et al., 2002; Sharma Mahendra et al., 2008) and this study indicate that sex with multiple partners, receptive anal sex and inconsistent condom use continue to make this community vulnerable to STIs and HIV/AIDS. Future prevention interventions should consider risk reduction strategies that promote the reduction of sexual partners, consistent condom use and encouraging inter-femoral sex rather than oral or anal sex, alcohol intervention and periodic screening and treatment of STIs. In addition, male-to-female transgender people should be considered for focused targeted interventions which increase the risk perception of the male-to-female transgender community towards STIs and HIV.

Limitations of the study: Since the male-to-female transgender people practice receptive anal sex with multiple partners, ano-rectal swabs have a better possibility of detecting C. trachomatis and N. gonorrhoea instead of from urine samples. But the non-accessibility of the M-24 transport medium during the study period limited collection of ano-rectal swabs and instead only urine sample was used for diagnosing $C$. trachomatis and N. gonorrhoea. Similarly, the convenience sampling adopted limits the extent to which the study findings may be generalized to the entire population.

\section{CONCLUSION}

We conclude that the low risk perception of the male-to-female transgender people towards STIs and HIV and the practice of high risk sexual behaviors such as multiple partners, anal and oral sex, inconsistent condom usage and alcohol consumption during sex, is all factors that should be considered when designing community -specific and evidence-based interventions.

\section{ACKNOWLEDGEMENT}

The authors acknowledge the Tamil Nadu State AIDS Control Society, Transgender and MSM organizations and the transgender community in Chennai for their support. P.S. acknowledges training support from the AIDS International Training and Research Program (NIH D43-TW01403) of the Albert Einstein College of Medicine, New York.

\section{REFERENCES}

Benegal, V., 2005. India: Alcohol and public health. Addiction, 100: 1051-1056. DOI: 10.1111/j.13600443.2005.01176.x
Brahmam, G.N., V. Kodavalla, H. Rajkumar, H.K. Rachakulla and S. Kallam et al., 2008. Sexual practices, HIV and sexually transmitted infections among self-identified men who have sex with men in four high HIV prevalence states of India. AIDS, 22: S45-S57. DOI: 10.1097/01.aids.0000343763.54831.15

Christine, E.K., C.T. Halpern, W.C. Miller and C.A. Ford, 2005. Young age at first sexual intercourse and sexually transmitted infections in adolescents and young adults. Am. J. Epidemiol., 161: 774-780. DOI: $10.1093 /$ aje/kwi095

Cowan, F.M., A. Copas, A. Johnson, R. Ashley L. Corey and A. Mindel 2002. Herpes simplex virus type 1 infection: A sexually transmitted infection of adolescence. Sex. Transmit. Infect., 78: 346-348. DOI: $10.1136 /$ sti.78.5.346

Graham, A., 2004. Sexual health. Br. J. Gen. Pract., 54: 382-387. PMCID: PMC1266175

Harrison, A, J. Cleland, E. Gouws and J. Frohlich, 2005. Early sexual debut among young men in rural South Africa: Heightened vulnerability to sexual risk. Sex. Transmit. Infect., 81: 259-261. DOI: $10.1136 /$ sti.2004.011486

Jeffrey, H. and E.D. Herbst, 2008. Estimating HIV prevalence and risk behaviors of transgender persons in the united states: A systematic review. AIDS Behav., 12: 1-17. http://www.ncbi.nlm.nih.gov/pubmed/17694429.

Kenagy, G.P., 2005. Transgender Health: Findings from two needs assessment studies in Philadelphia. Health Soc. Work, 30: 19-26. http://www.ncbi.nlm.nih.gov/pubmed/15847234

Kira, H. and V. O’Donovan, 1996. Shifting Gender Positions Among Hindi-Speaking Hijras. In: Rethinking Language and Gender Research: Theory and Practice, Bergvall, V., J. Bing and A. Freed (Eds.). London, pp: 228-266.

Khan, A., 2006. Differences in sexual behaviors of male commercial sex workers (MSWs) and transgenders/transvestites (Hijras) in Pakistan. Proceeding of the 16th International AIDS Conference, Aug. 13-18, Toronto, Canada, pp: 1-1. http://www.aegis.com/conferences/iac/2006/TuPd D07.html

Kumta, S., M. Setia, H. R. Jerajani, M.S. Mathur and A. RaoKAvi et al., 2002. Men who have sex with men (msm) and male-to-female Transgender (TG) in Mumbai: A critical emerging risk group for HIV and sexually transmitted infections (STI) in India. Proceeding of the 14th International Conference on AIDS, July 7-12, Barcelona, Spain, pp: 1-1. http://gateway.nlm.nih.gov/MeetingAbstracts/ma?f $=102255426 . h \mathrm{html}$ 
Kumta, S., M. Lurie, A. Gogate, H. Jerajani and S. Weitzen, 2006. Sexual risk behavior and HIV prevalence among male-to-female transgendered people seeking voluntary counseling and testing services in Mumbai, India. Proceeding of the 16th International AIDS Conference, Aug. 13-18, Toronto, Canada, pp: 1-1. http://www.aegis.com/conferences/iac/2006/MoAd 0303.html

Khan, A.A., N. Rehan, K. Qayyum and A. Khan, 2008. Correlates and prevalence of HIV and sexually transmitted Infections among Hijras (male transgenders) in Pakistan. Int. J. STD AIDS, 19: 817-820. DOI: 10.1258/ijsa.2008.008135

Lydié, N.R.N., 2004. Mobility, Sexual behavior and HIV infection in an urban population in Cameroon. J. Acquir. Immune. Defic. Syndr., 35: 67-74. http://www.ncbi.nlm.nih.gov/pubmed/14707795

Mishra, S.M., 2009. Sex work, syphilis and seeking treatment: An opportunity for intervention in HIV prevention programming in Karnataka, South India. Sex. Transmit. Dis., 36: 157-164. DOI: 10.1097/OLQ.0b013e31818d64e6

National Alliance of State and Territorial AIDS Directors, (NASTAD), 2009. Global program country profile: India. http://www.nastad.org/Docs/Public/Publication/20 0969_India\%20Country\%20Profile\%202009\%20fi nal.pdf

National AIDS Control Organization, (NACO), 2008. Note on HIV sentinel surveillance and HIV estimation.

https://nacoonline.org/upload/NACO\%20PDF/Not e\%20on\%20HIV\%20Sentinel\%20Surveillance $\% 20$ and\%20HIV\%20Estimation_01\%20Feb\%2008.pdf
Pisani, E.G., P. Girault, M. Gultom, N. Sukartini and J. Kumalawati et al., 2004. HIV syphilis infection and sexual practices among transgenders, male sex workers and other men who have sex with men in Jakarta, Indonesia. Sex. Transmit. Infect., 80: 536-540. DOI: $10.1136 /$ sti.2003.007500

Rani, S., 2008, Prostitution: A burning issue in India today. http://www.merinews.com/article/prostitution-aburning-issue-in-india-today/131963.shtml

Sharma Mahendra, V., R. Verma, S. Singh, S. Kapoor and M. Prakasamma et al., 2008. Vulnerability to HIV/STIs among MSM and transgender populations in India-implications for AIDS prevention research.

http://www.iasociety.org/Default.aspx?pageId=11 \&abstractId $=200720497$

Silva, K.T., S.L. Schensul, P. Ratnayake and B. Nastasi, 1996. Sexual risk and cultural perceptions of sexual risk among young people in Sri Lanka. Proceeding of the International Conference on AIDS. July 7-12, University of Peradeniya, Peradeniya, Sri Lanka, pp: 1-1. http://gateway.nlm.nih.gov/MeetingAbstracts/ma?f $=102220295 . \mathrm{html}$

Simoes, E.A., 1987. Evidence for HTLV-III infection in prostitutes in Tamil Nadu (India). Indian J. Med Res., 87: 335-338. http://www.ncbi.nlm.nih.gov/pubmed/3623641

Venkatesan, C., Priya Babu and T. Ebenezer 2004. Hijras in sex work face discrimination in Indian health-care system. http://www.popline.org/docs/1507/273322.html

World Health Organization, (WHO), 1999. Guidelines for the implementation of STI prevalence surveys. Sexually transmitted infections prevalence study methodology. Regional Office for the Western Pacific. http://www.wpro.who.int/internet/resources.ashx/H SI/docs/Guidelines_for_the_Implementation_of_S TI_Prevalence_Surveys.pdf 